\title{
CC-chemokine ligand 2 inhibition in idiopathic pulmonary fibrosis: a phase 2 trial of carlumab
}

\author{
Ganesh Raghu1, Fernando J. Martinez², Kevin K. Brown ${ }^{3}$, Ulrich Costabel ${ }^{4}$, \\ Vincent Cottin ${ }^{5}$, Athol U. Wells ${ }^{6}$, Lisa Lancaster ${ }^{7}$, Kevin F. Gibson ${ }^{8}$, \\ Tarik Haddad ${ }^{9}$, Prasheen Agarwal ${ }^{10}$, Michael Mack $^{10}$, Bidisha Dasgupta $^{10}$, \\ Ivo P. Nnane ${ }^{10}$, Susan K. Flavin ${ }^{10}$ and Elliot S. Barnathan ${ }^{10}$
}

Affiliations: ${ }^{1}$ Division of Pulmonary and Critical Care Medicine, University of Washington Medical Center, Seattle, WA, USA. ${ }^{2}$ Division of Pulmonary and Critical Care Medicine, University of Michigan, Ann Arbor, MI, USA. ${ }^{3}$ Department of Medicine, National Jewish Health, Denver, CO, USA. ${ }^{4}$ Ruhrlandklinik, University Hospital, University of Duisburg-Essen, Essen, Germany. ${ }^{5}$ National Reference Centre, Department of Respiratory Medicine, Claude Bernard Lyon 1 University, Hospices Civils de Lyon, Lyon, France. ${ }^{6}$ Royal Brompton Hospital, Imperial College London NHS Healthcare Trust, London, UK. ${ }^{7}$ Division of Allergy, Pulmonary and Critical Care Medicine, Vanderbilt University, Nashville, TN, USA. ${ }^{8}$ Division of Pulmonary, Allergy and Critical Care Medicine, University of Pittsburgh School of Medicine, Pittsburgh, PA, USA. ${ }^{9}$ New Lung Associates, Tampa, FL, USA. ${ }^{10}$ Janssen Research \& Development LLC, Spring House, PA, USA.

Correspondence: Ganesh Raghu, Campus Box 356175, University of Washington, Seattle, WA 98195-6522, USA. E-mail: graghudu.washington.edu

ABSTRACT The objective of this study was to determine the safety and efficacy of carlumab in the treatment of idiopathic pulmonary fibrosis (IPF).

A phase 2, randomised, double-blind placebo-controlled dose-ranging study was conducted in patients with IPF ( $\mathrm{n}=126)$. Patients were randomised to carlumab $\left(1 \mathrm{mg} \cdot \mathrm{kg}^{-1}, 5 \mathrm{mg} \cdot \mathrm{kg}^{-1}\right.$, or $\left.15 \mathrm{mg} \cdot \mathrm{kg}^{-1}\right)$ or placebo every 4 weeks. The primary endpoint was the rate of percentage change in forced vital capacity (FVC). Secondary endpoints were time to disease progression, absolute change in FVC, relative change in diffusing capacity of the lung for carbon monoxide (DLCO), and St George's Respiratory Questionnaire (SGRQ) total score.

Due to a pre-planned, unfavourable interim benefit-risk analysis, dosing was suspended. The rate of percentage change in FVC showed no treatment effect (placebo $-0.582 \%, 1 \mathrm{mg} \cdot \mathrm{kg}^{-1}-0.533 \%, 5 \mathrm{mg} \cdot \mathrm{kg}^{-1}$ $-0.799 \%$ and $\left.15 \mathrm{mg} \cdot \mathrm{kg}^{-1}-0.470 \% ; \mathrm{p}=0.261\right)$. All active treatment groups showed a greater decline in FVC $\left(1 \mathrm{mg} \cdot \mathrm{kg}^{-1}-290 \mathrm{~mL}, 5 \mathrm{mg} \cdot \mathrm{kg}^{-1}-370 \mathrm{~mL}\right.$ and $\left.15 \mathrm{mg} \cdot \mathrm{kg}^{-1}-320 \mathrm{~mL}\right)$ compared with placebo $(-130 \mathrm{~mL})$. No effect on disease progression, DLCO, infection rates or mortality was observed. SGRQ scores showed a nonsignificant trend toward worsening with active treatment. Unexpectedly, free CC-chemokine ligand 2 levels were elevated above baseline at both 24 and 52 weeks. A higher proportion of patients with one or more serious adverse events was observed in the $5 \mathrm{mg} \cdot \mathrm{kg}^{-1}$ group (53.1\%) compared with $1 \mathrm{mg} \cdot \mathrm{kg}^{-1}(15.2 \%)$, $15 \mathrm{mg} \cdot \mathrm{kg}^{-1}(21.9 \%)$ and placebo (46.4\%), although no unexpected serious adverse events were noted.

Although dosing was stopped prematurely, it is unlikely that carlumab provides benefit to IPF patients.

@ERSpublications

It is unlikely that carlumab provides benefit to patients with idiopathic pulmonary fibrosis http://ow.ly/QUztq

This article has supplementary material available from erj.ersjournals.com

Received: Aug 252014 | Accepted after revision: July 12 2015 | First published online: Oct 222015

Clinical trial: This study is registered at clinicaltrials.gov with identifier number NCT00786201.

Support statement: Janssen Research \& Development, LLC supported this research.

Conflict of interest: Disclosures can be found alongside the online version of this article at erj.ersjournals.com

Copyright OERS 2015 


\section{Introduction}

Idiopathic pulmonary fibrosis (IPF), a fibrotic lung disease within the group of idiopathic interstitial pneumonias, is a distinct clinical entity occurring in adults and limited to the lungs $[1,2]$. The progressive accumulation of parenchymal fibrosis results in distorted pulmonary architecture, functional impairment and death [1]. Therapeutic options are limited.

IPF typically develops between the ages of 40 and 70 years of age $[1,3]$. The disease affects $\sim 5$ million people globally and appears to be increasing in prevalence [4]. Despite recent advances, IPF remains generally refractory to current pharmacological therapy and is invariably fatal, with a median survival of 3-5 years [5, 6]. Since publication of the 2011 evidence-based guidelines for diagnosis and management of IPF, more recently published randomised trials suggest that treatment with prednisone plus azathioprine and $\mathrm{N}$-acetylcysteine [7] and warfarin [8] are associated with increased mortality. Other recent studies have suggested beneficial effects of antigastro-oesophageal reflux therapy in patients with IPF $[9,10]$. Both pirfenidone and nintedanib have been approved in several countries, including USA more recently, for the treatment of patients with IPF. For many IPF patients, lung transplantation is one other viable option, but is limited to the small subgroup of patients who are eligible.

CC-chemokine ligand (CCL)2 is a chemoattractant for T-cells, natural killer cells and fibrocytes [11-13] and is believed to play a role in inflammation, cell activation and migration, angiogenesis and fibrosis $[14,15]$ through the G-protein coupled, seven-transmembrane spanning CC-chemokine receptor 2 [16]. CCL2 is a chemokine that has been shown to be associated with a wide variety of diseases states including thrombus formation [17], tuberculosis [18], recurrent miscarriage [19], allergic asthma [20] and rheumatoid arthritis [21], among others. The involvement of CCL2 in these diseases has been demonstrated using genetically deficient mice, antibody- or inhibitor-mediated neutralisation in mice and in epidemiological studies [22]. Although CCL2 has been associated with many pathological conditions, attempts to reduce CCL2 production to achieve clinical benefit needs to be cautiously balanced due to its role in routine health maintenance.

CCL2 remains one of the most studied chemokines. Valuable information regarding its pathway has come from various structure-functional and transgenic mouse models. A strong link was found between CCL2 polymorphism and autoimmune diseases. CCL2 $(-2518 \mathrm{~A} / \mathrm{G})$ single nucleotide polymorphism has been shown to be associated with the chronic stable angina pectoris [23], and a significant but not independent association was observed between the (-2518G/A) polymorphism of the CCL2 gene and myocardial infarction [24]. This single nucleotide polymorphism has also been shown to be involved with pulmonary sarcoidosis [25].

Although the pathogenesis of IPF is not fully understood, the disease is believed to be mediated by unprovoked, repeated injury to the alveolar epithelium, which leads to the formation of distinct subepithelial fibroblast/myofibroblast foci and excessive extracellular matrix accumulation driven by overexpression of chemotactic and profibrotic chemokines. These processes lead to progressive fibrosis and a rapid, terminal disease course $[5,26,27]$. Elevated CCL2 levels have been found in the blood and bronchoalveolar lavage of IPF patients [28]. In vitro and in vivo studies have shown that CCL2 contributes to fibrosis by supporting monocyte/macrophage inflammatory response, angiogenesis, fibroblast collagen synthesis, myofibroblast differentiation and fibroblast recruitment and survival $[15,29]$.

Carlumab is a human immunoglobulin $G_{1 \kappa}$ monoclonal antibody that specifically binds and neutralises profibrotic activities of human CCL2. We hypothesised that such a therapeutic approach would prove valuable in IPF. Herein, we report the efficacy, safety, pharmacokinetics and pharmacodynamics findings from a phase 2 study of carlumab administered to patients with progressive IPF despite treatment with currently available therapies.

\section{Methods}

Patients

Patients aged 40-80 years were eligible if they had been diagnosed with IPF according to the 2000 American Thoracic Society (ATS)/European Respiratory Society (ERS) criteria [3] within 4 years of screening. Patients were required to have progressive IPF disease (one or more of the following within 12 months: relative decrease of $\geqslant 10 \%$ in forced vital capacity (FVC), relative decrease of $\geqslant 15 \%$ in diffusing capacity of the lung for carbon monoxide ( $D \mathrm{LCO}$ ), evidence of clinically significant worsening on high-resolution computed tomography (HRCT) or significant worsening of dyspnoea at rest or with exertion) based on a modified version of the 2000 ATS/ERS criteria, despite currently available, conventional treatment per the ATS/ERS consensus statement. Patients must have had evidence of stability of $\%$ predicted FVC (defined as not having changed $>15 \%$ at the baseline visit relative to the screening visit) with no suspected active or history of latent tuberculosis. For key exclusion criteria and allowed concomitant medications, see the online supplementary material. All patients provided written informed 
consent. The institutional review board or independent ethics committee at each site approved the protocol which was conducted according to the principles of the Declaration of Helsinki and the International Conference on Harmonisation guidelines for good clinical practice.

\section{Study design}

This was a multicentre, international, double-blind placebo-controlled dose-ranging study. Patients were randomly assigned by interactive voice-response system in a 1:1:1:1 ratio, stratified by high-risk category (yes/no) and baseline oral corticosteroid (OCS) use (yes/no), to receive intravenous infusions of placebo or $1 \mathrm{mg} \cdot \mathrm{kg}^{-1}, 5 \mathrm{mg} \cdot \mathrm{kg}^{-1}$, or $15 \mathrm{mg} \cdot \mathrm{kg}^{-1}$ carlumab every 4 weeks for 48 weeks. High risk was defined as significant honeycombing on HRCT (as interpreted by the investigator), oxygen desaturation ( $<88 \%)$ during the 6 -min walk test at screening or FVC $<60 \%$ pred at screening. Patients had follow-up visits at weeks 52 , 60 and 72 to assess safety, pharmacokinetics, pharmacodynamics and maintenance of clinical effects.

\section{Efficacy evaluations}

The primary endpoint was the rate of percentage change in FVC per 4-week interval through week 52. Major secondary endpoints assessed at week 52 included time to disease progression (defined as either an acute IPF exacerbation, lung transplantation, $\geqslant 10 \%$ decrease from baseline in FVC, $\geqslant 15 \%$ decrease from baseline in DLCO or all-cause mortality); absolute change from baseline in FVC (mL); relative change from baseline in DLCO; and change from baseline in St George's Respiratory Questionnaire (SGRQ) total score. Investigators were provided with an algorithm for the diagnosis and management of acute exacerbations since there was no consensus definition on the diagnosis at the time of protocol design. Prespecified subgroup analyses were age, race, sex, investigational site region, baseline FVC, DLCO, 6-min walking distance (6MWD), serum CCL2, SGRQ total score, high-risk category, use of OCS at baseline, proton pump inhibitor use at baseline and respiratory-related hospitalisations or emergency room visits in the last year. Spirometry tests were performed at every study visit except week 60. DLCO was measured during screening and at weeks 12, 24, 36, 52 and 72. HRCT scans were obtained at the start of the study and at week 52, and were read, interpreted and scored at a central core laboratory by two readers blinded to treatment assignment. If adjudication was required (based upon a scoring differential of $>1$ point difference on a 5-point Likert scale), a third independent reviewer evaluated the scans and issued an interpretation.

\section{Safety evaluations}

Safety assessments included physical examinations, ECGs, routine blood and urine analyses and monitoring for adverse events. An external data monitoring committee (DMC) performed unblinded reviews of safety data at regularly scheduled intervals throughout the study. In addition, a pre-planned, interim DMC review evaluated both efficacy and safety data and included a benefit-risk analysis after all patients completed the week 24 visit.

\section{Pharmacokinetics}

Serum samples were collected to evaluate carlumab pharmacokinetics, immune response and pharmacodynamics (online supplementary material).

\section{Statistical analyses}

The primary endpoint analysis included all randomised patients who received at least one infusion (partial or complete). A linear mixed-effect model using FVC assessments through week 52 was used to estimate the primary endpoint of the rate of percentage change in FVC by treatment group and to assess the treatment effect. The primary hypothesis was that the $5 \mathrm{mg} \cdot \mathrm{kg}^{-1}$ and $15 \mathrm{mg} \cdot \mathrm{kg}^{-1}$ carlumab treatments combined or individually would be superior to placebo. The study would be considered positive if the overall combined $5 \mathrm{mg} \cdot \mathrm{kg}^{-1}$ and $15 \mathrm{mg} \cdot \mathrm{kg}^{-1}$ groups achieved statistical significance and at least one of the $5 \mathrm{mg} \cdot \mathrm{kg}^{-1}$ or $15 \mathrm{mg} \cdot \mathrm{kg}^{-1}$ groups was also significantly better than placebo. All comparisons were performed using a two-sided 0.05 level of significance.

Due to the small size of each dose group and the relatively high mortality in this population, this study used a novel approach to stratify patients at increased risk of early mortality (high-risk status) and for the use of OCS to ensure that important baseline risk factors for mortality were equally distributed among the groups. Missing DLCO and SGRQ data were imputed using the last observation carried forward approach; sensitivity analyses were also run with missing data excluded. Count data were analysed based on the Cochran-Mantel-Haenszel row mean score test. Categorical data were analysed using Fisher's exact test (for dichotomous variables) or the Pearson Chi-squared test (for variables with more than two categories). 


\section{Results}

\section{Baseline patient characteristics}

Of the 126 patients randomised at sites in Belgium, Canada, Germany, the Netherlands and USA between October 2008 and January 2012, 125 patients were treated and comprised the modified intent-to-treat (ITT) population (fig. 1). One patient, randomised to the placebo group, withdrew consent. Among the randomised patients, the median (range) age was 66 (42-80) years; most were men ( $\mathrm{n}=101,80 \%)$ and Caucasian $(\mathrm{n}=124,98 \%)$. At baseline, most $(\mathrm{n}=81,64 \%)$ patients were considered high risk and $20(16 \%)$ patients were receiving OCS (mean dose $13.3 \mathrm{mg}$ ). All baseline characteristics were similar except for a lower FVC $\%$ pred in the $5 \mathrm{mg} \cdot \mathrm{kg}^{-1}$ group (table 1 ).

\section{Study participation and sponsor decision to discontinue treatment}

64 (51\%) out of the 126 randomised patients completed the study through week 72 , and $58 \%$ completed dosing through week 48 when the DMC recommended to halt dosing in the two highest dose groups, based on the pre-planned benefit-risk analysis conducted after all patients completed $\geqslant 24$ weeks of dosing. Based on that recommendation, the sponsor discontinued all further dosing and encouraged all remaining patients to return for safety follow-up visits for 24 weeks after the last dose of study agent, to be consistent with the planned follow-up for the study population as a whole. $62(49 \%)$ out of the 126 patients in the study terminated participation. Prior to the sponsor directive to discontinue treatment, 38 (30\%) patients terminated study participation for reasons including consent withdrawal $(n=16)$, death $(n=13)$ or other reasons $(n=9)$. After the sponsor directive, reasons included consent withdrawal $(n=7)$, death $(n=1)$, other reasons $(n=2)$ or directive to discontinue treatment with carlumab $(n=14)$.

\section{Efficacy}

The primary endpoint analysis for the modified ITT population showed no statistically significant treatment effect on rate of change in FVC per 4-week interval through week 52 from any carlumab dose ( $\mathrm{p}=0.261)$. Rates \pm SE of percentage change from baseline were $-0.582 \pm 0.16 \%$ in the placebo group, $-0.533 \pm 0.14 \%$ in the $1 \mathrm{mg} \cdot \mathrm{kg}^{-1}$ group, $-0.799 \pm 0.15 \%$ in the $5 \mathrm{mg} \cdot \mathrm{kg}^{-1}$ group and $-0.470 \pm 0.16 \%$ in the $15 \mathrm{mg} \cdot \mathrm{kg}^{-1}$ group (fig. $2 \mathrm{a}$ and table 2). All groups demonstrated a worsening in FVC over time; however, the groups treated with carlumab tended to do worse than placebo (fig. 2b). Additionally, pre-specified subgroup analyses conducted for demographic and disease characteristics showed no improvement in rate of percent change in FVC for treatment with carlumab $5 \mathrm{mg} \cdot \mathrm{kg}^{-1}$ or $15 \mathrm{mg} \cdot \mathrm{kg}^{-1}$ compared with placebo (online supplementary table S1).

In secondary endpoint analyses, no active treatment group showed a benefit in terms of time to disease progression, absolute change from baseline FVC or relative change from baseline DLCO when compared with placebo (table 3). Based on the sensitivity analyses with no missing data imputation there were small

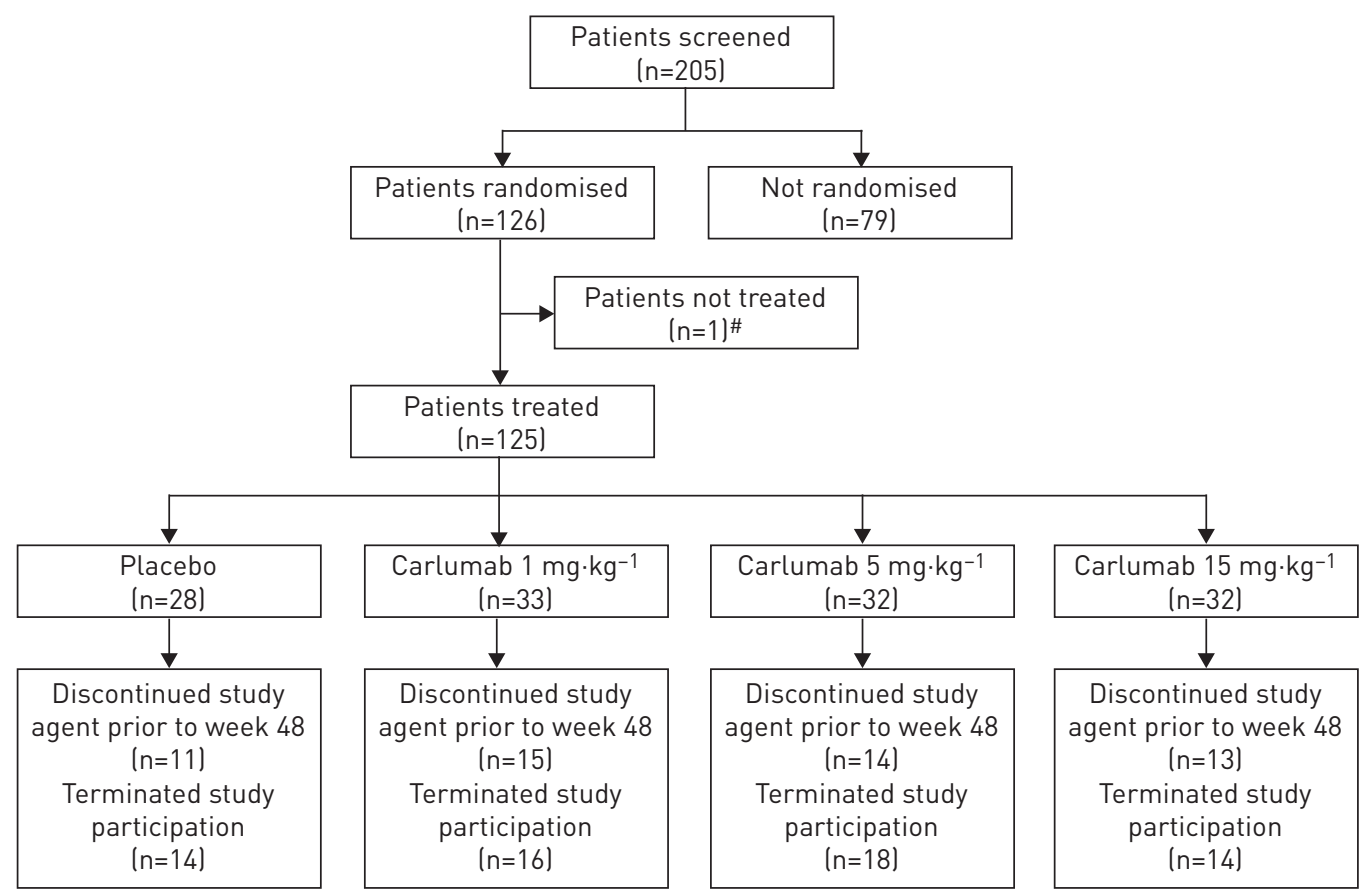

FIGURE 1 Patient disposition. " : the patient was randomised to the placebo group. 
TABLE 1 Patient demographics and disease characteristics at baseline

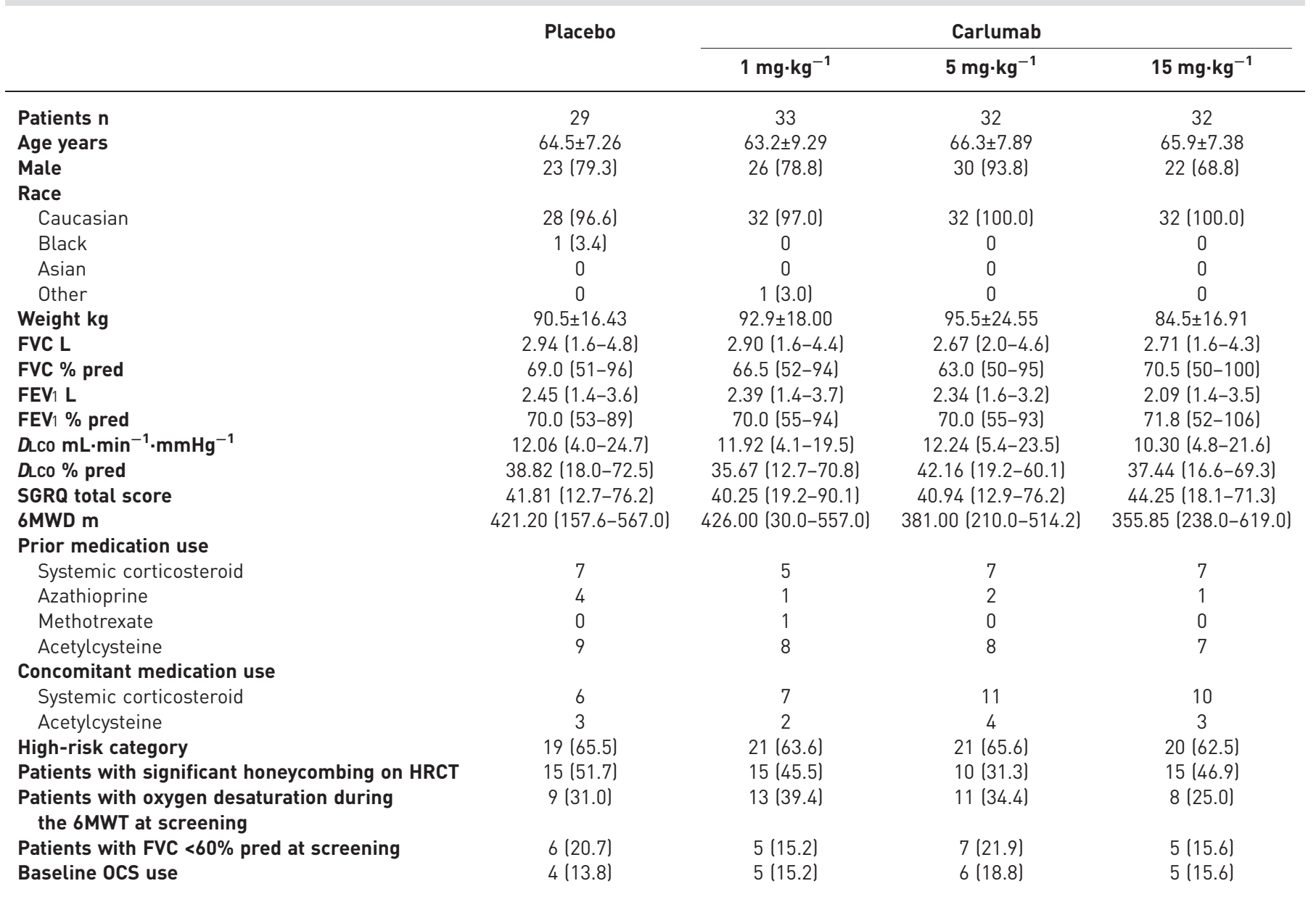

Data are presented as $\mathrm{n}$, mean $\pm \mathrm{SD}, \mathrm{n}(\%)$ or median (range). FVC: forced vital capacity; \% pred: \% predicted; FEV 1 : forced expiratory volume in $1 \mathrm{~s} ;$ DLCo: diffusing capacity of the lung for carbon monoxide; SGRQ: St George's Respiratory Questionnaire; 6MWD: 6-min walking distance; HRCT: high-resolution computed tomography; 6MWT: 6-min walk test; OCS: oral corticosteroids.
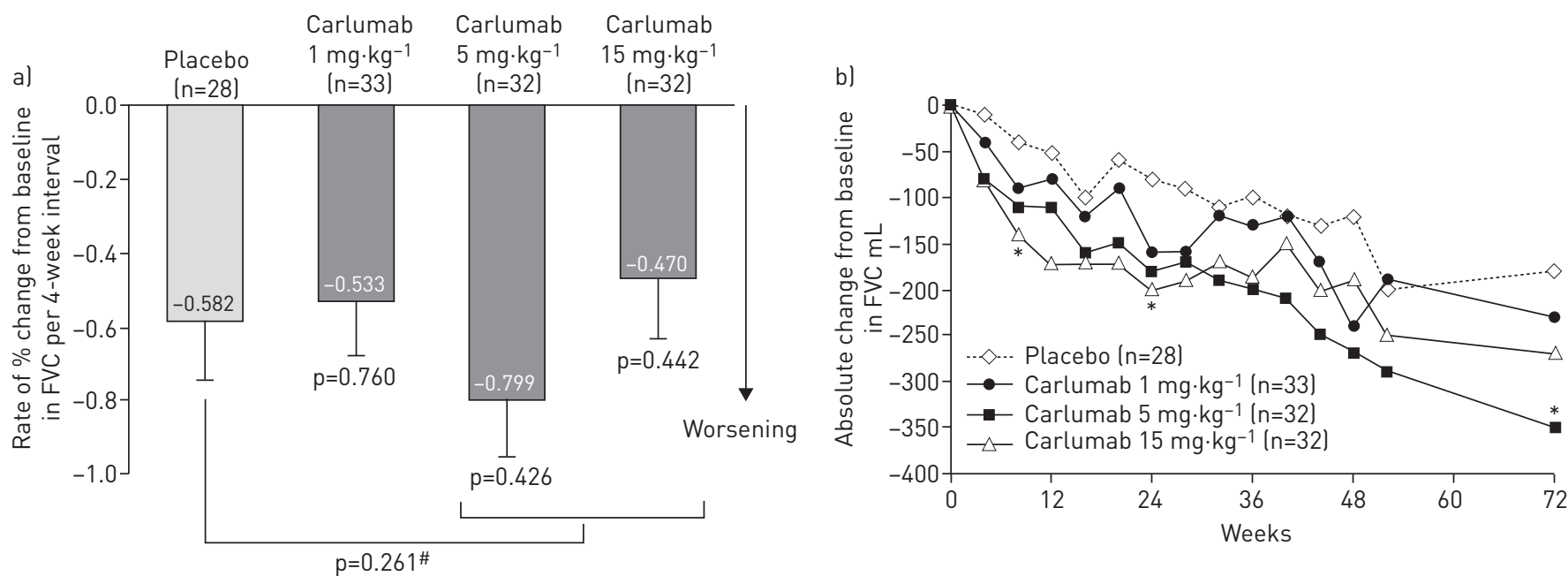

FIGURE 2 a) Least squares mean rate of percentage change in forced vital capacity (FVC) per 4-week interval from baseline through week 52 comparing the $5 \mathrm{mg} \cdot \mathrm{kg}^{-1}(\mathrm{p}=0.426)$ and $15 \mathrm{mg} \cdot \mathrm{kg}^{-1}(\mathrm{p}=0.442)$ to placebo. ${ }^{\#}$ : overall $\mathrm{p}$-value of the combined $5 \mathrm{mg} \cdot \mathrm{kg}^{-1}$ and $15 \mathrm{mg} \cdot \mathrm{kg}^{-1} \mathrm{groups}$ compared with placebo $(p=0.261)$. b) Least squares mean absolute change from baseline in FVC. *: $p<0.05$ compared with placebo; in all other comparisons, the $p$-value was nonsignificant. 
TABLE 2 Change from baseline forced vital capacity (FVC) through week 52 in modified intent-to-treat patients

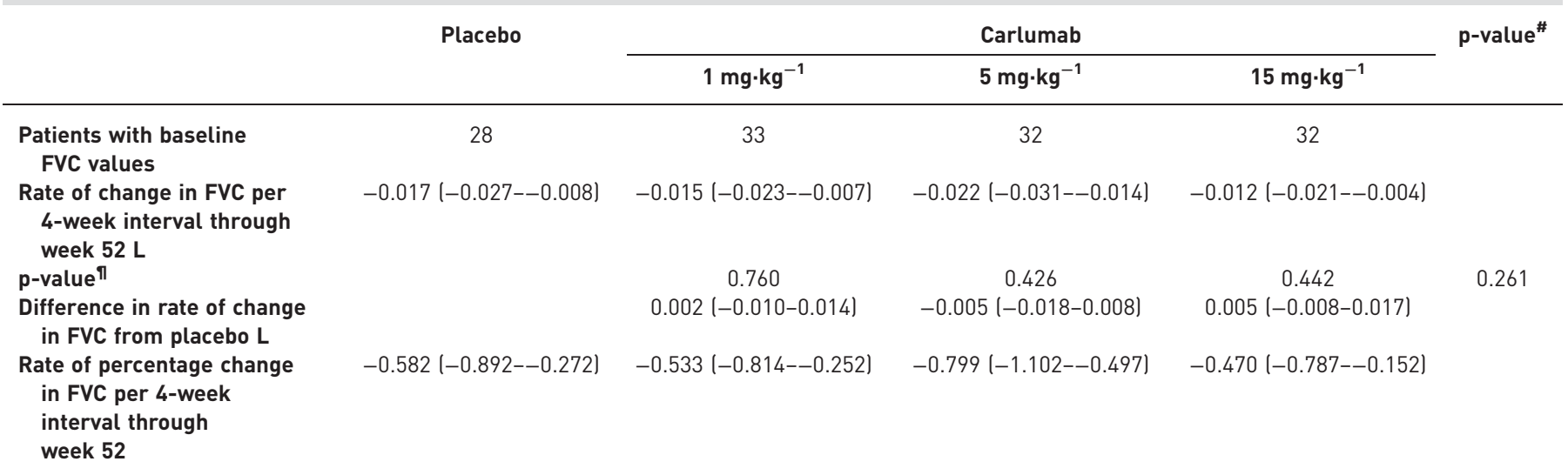

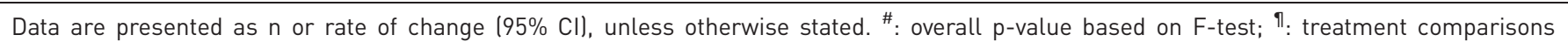
based on linear contrasts.

differences in change for DLCO; the results were more problematic for SGRQ, where p-values were $>0.2$ when not imputing at all, while last observation carried forward methodology nearly shows significant worsening for $5 \mathrm{mg} \cdot \mathrm{kg}^{-1}$ and $15 \mathrm{mg} \cdot \mathrm{kg}^{-1}$.

Because exercise capacity, measured by the $6 \mathrm{MWD}$, has been shown in previous studies to correlate with survival in patients with IPF [30, 31], 6MWD was also analysed. Post hoc analyses found that in this study population, only the use of OCS and a $6 \mathrm{MWD}<260 \mathrm{~m}$ were significantly associated with higher mortality, while high-risk status alone was not. The presence of any two of these three factors (i.e. use of OCS, 6MWD

TABLE 3 Key efficacy variables at week 52 in modified intent-to-treat patients

\begin{tabular}{|c|c|c|c|c|}
\hline & \multirow[t]{2}{*}{ Placebo } & \multicolumn{3}{|c|}{ Carlumab } \\
\hline & & $1 \mathrm{mg} \cdot \mathrm{kg}^{-1}$ & $5 \mathrm{mg} \cdot \mathrm{kg}^{-1}$ & $15 \mathrm{mg} \cdot \mathrm{kg}^{-1}$ \\
\hline \multicolumn{5}{|l|}{ Time to disease progression } \\
\hline $\begin{array}{l}\text { Patients with disease progression } \\
\text { through week } 52\end{array}$ & $3(10.7)$ & $4(12.1)$ & 7 (21.9) & $3(9.4)$ \\
\hline Hazard ratio $(95 \% \mathrm{Cl})$ & & $1.078(0.24-4.86)$ & $1.977(0.51-7.72)$ & $0.852(0.17-4.26)$ \\
\hline Lung transplants & 0 & $3(9.1)$ & 0 & 0 \\
\hline Acute IPF exacerbations & 0 & $2(6.1)$ & $3(9.4)$ & $2(6.3)$ \\
\hline Based on HRCT assessment & & 0 & 1 & 1 \\
\hline Based on investigator assessment & & 2 & 3 & 1 \\
\hline \multicolumn{5}{|l|}{ Absolute change from baseline $\mathrm{FVC} \mathrm{mL}$} \\
\hline Patients with baseline FVC values & 28 & 33 & 32 & 32 \\
\hline Least squares $\%$ & $-0.10 \pm 0.056(-0.21-0.01)$ & $-0.08 \pm 0.052(-0.19-0.02)$ & $-0.22 \pm 0.052(-0.33--0.12)$ & $-0.07 \pm 0.053(-0.17-0.04)$ \\
\hline $\mathrm{p}$-value & & 0.804 & 0.068 & 0.621 \\
\hline \multicolumn{5}{|l|}{ Change from baseline SGRQ at week 52} \\
\hline Patients with baseline $S G R Q$ values & 27 & 32 & 32 & 31 \\
\hline Least squares $\%$ & $-0.41 \pm 2.315(-5.00-4.17)$ & $2.73 \pm 2.173(-1.57-7.04)$ & $4.74 \pm 2.098(0.59-8.90)$ & $4.31 \pm 2.155(0.04-8.58)$ \\
\hline $\mathrm{p}$-value & & 0.259 & 0.065 & 0.093 \\
\hline \multicolumn{5}{|c|}{$\begin{array}{l}\text { Data are presented as } \mathrm{n}, \mathrm{n}(\%) \text { or mean } \pm \mathrm{SE}(95 \% \mathrm{CI}) \text {, unless otherwise stated. IPF: idiopathic pulmonary fibrosis; HRCT: high-resolution computed } \\
\text { tomography; FVC: forced vital capacity; DLC: diffusing capacity of the lung for carbon monoxide; SGRQ: St George's Respiratory Questionnaire. } \\
\# \text { : based on Cox proportional hazards model stratified by high-risk category (yes/nol and baseline use of oral corticosteroids (yes/no). }\end{array}$} \\
\hline
\end{tabular}


$<260 \mathrm{~m}$ or high-risk status) was associated with higher mortality (two or more present $42.3 \%$; one present 9.5\%; and none present 5.6\%), while treatment with carlumab was not. Since the use of OCS was not randomised, it is not clear whether it is a marker of more severe disease or whether it confers toxicity in combination with other immunosuppressants as in the PANTHER-IPF (Prednisone, Azathioprine, and $N$-Acetylcysteine: a Study that Evaluates Response in Idiopathic Pulmonary Fibrosis) study [7]. While these results should be interpreted with caution, given the small sample size and post hoc nature of these analyses, prospective risk stratification for significant baseline predictors of early mortality may be a useful design feature for future trials in IPF.

\section{Safety}

A higher proportion of patients with one or more serious adverse events (SAEs) was observed in the $5 \mathrm{mg} \cdot \mathrm{kg}^{-1}$ group (53.1\%) compared with other treatment groups: $1 \mathrm{mg} \cdot \mathrm{kg}^{-1}$ (15.2\%), $15 \mathrm{mg} \cdot \mathrm{kg}^{-1}(21.9 \%)$ and placebo (46.4\%) (table 4). The greatest proportion of SAEs was reported in the respiratory, thoracic and mediastinal disorders system organ class (SOC) and was higher in the carlumab $5 \mathrm{mg} \cdot \mathrm{kg}^{-1}$ group (28.1\%), compared with $17.9 \%, 6.1 \%$ and $15.6 \%$ in the placebo, $1 \mathrm{mg} \cdot \mathrm{kg}^{-1}$ and $15 \mathrm{mg} \cdot \mathrm{kg}^{-1}$ groups, respectively. Worsening of IPF was the most commonly reported SAE from within the respiratory, thoracic and mediastinal disorders SOC for the carlumab and placebo groups: $1 \mathrm{mg} \cdot \mathrm{kg}^{-1}(6.1 \%), 5 \mathrm{mg} \cdot \mathrm{kg}^{-1}$ (18.8\%), $15 \mathrm{mg} \cdot \mathrm{kg}^{-1}(9.4 \%)$ and placebo (14.3\%). The most frequently reported adverse events $(>20 \%)$ in patients treated with carlumab were cough, fatigue, upper respiratory tract infection, dyspnoea and IPF. Other frequent adverse events (10-20\%) were nasopharyngitis, headache, back pain, bronchitis, diarrhoea, nausea, arthralgia and pyrexia. Patients with one or more reasonably related adverse events, reported in $\geqslant 5 \%$ of patients, are presented in table 5 . There appeared to be no evidence of a dose response.

Reasons for discontinuation of therapy varied across the study population. In general, no trends for reasons for discontinuation were observed. Four (14\%) patients in the placebo group, five (15\%) patients in the $1 \mathrm{mg} \cdot \mathrm{kg}^{-1}$ group, nine (28\%) patients in the $5 \mathrm{mg} \cdot \mathrm{kg}^{-1}$ group and five (16\%) patients in the $15 \mathrm{mg} \cdot \mathrm{kg}^{-1}$ group discontinued treatment due to adverse events.

The number of infections was numerically lower in the placebo group compared with any of the carlumab groups with $61 \%, 67 \%, 72 \%$ and $69 \%$ experiencing at least one infection in the placebo, $1 \mathrm{mg} \cdot \mathrm{kg}^{-1}$,

TABLE 4 Number of patients with one or more treatment-emergent serious adverse events for treated patients through the end of study by Medical Dictionary for Regulatory Activities system organ class

\begin{tabular}{|c|c|c|c|c|}
\hline & \multirow[t]{2}{*}{ Placebo } & \multicolumn{3}{|c|}{ Carlumab } \\
\hline & & $1 \mathrm{mg} \cdot \mathrm{kg}^{-1}$ & $5 \mathrm{mg} \cdot \mathrm{kg}^{-1}$ & $15 \mathrm{mg} \cdot \mathrm{kg}^{-1}$ \\
\hline Treated patients & 28 & 33 & 32 & 32 \\
\hline Mean duration of follow-up weeks & 61 & 61 & 59 & 59 \\
\hline Patients with $\geqslant 1$ adverse event & 28 & 32 & 32 & 32 \\
\hline Patients with serious adverse events & $13(46.4)$ & $5(15.2)$ & $17(53.1)$ & $7(21.9)$ \\
\hline \multicolumn{5}{|l|}{ System organ class/preferred term $\#$, } \\
\hline Respiratory, thoracic and mediastinal disorders & $5(17.9)$ & $2(6.1)$ & $9(28.1)$ & $5(15.6)$ \\
\hline Infections and infestations & 4 (14.3) & $1(3.0)$ & $6(18.8)$ & $1(3.1)$ \\
\hline Cardiac disorders & $2(7.1)$ & 0 & $4(12.5)$ & $1(3.1)$ \\
\hline General disorders and administration site conditions & $2(7.1)$ & $1(3.0)$ & $2(6.3)$ & $1(3.1)$ \\
\hline Metabolism and nutrition disorders & 0 & 0 & $1(3.1)$ & $1(3.1)$ \\
\hline Musculoskeletal and connective disorders & $1(3.6)$ & 0 & $2(6.3)$ & 0 \\
\hline $\begin{array}{l}\text { Neoplasms benign, malignant and unspecified } \\
\text { (including cysts and polyps) }\end{array}$ & 0 & 0 & $1(3.1)$ & $1(3.1)$ \\
\hline Nervous system disorders & $2(7.1)$ & $1(3.0)$ & $1(3.1)$ & 0 \\
\hline Renal and urinary disorders & $1(3.6)$ & 0 & $2(6.3)$ & 0 \\
\hline Ear and labyrinth disorders & 0 & 0 & 0 & $1(3.1)$ \\
\hline Gastrointestinal disorders & $2(7.1)$ & 0 & $1(3.1)$ & 0 \\
\hline Investigations & 0 & 0 & $1(3.1)$ & 0 \\
\hline Surgical and medical procedures & 0 & $1(3.0)$ & 0 & 0 \\
\hline Injury, poisoning and procedural complications & $1(3.6)$ & 0 & 0 & 0 \\
\hline Skin and subcutaneous tissue disorders & $1(3.6)$ & 0 & 0 & 0 \\
\hline
\end{tabular}

Data are presented as $\mathrm{n}$ or $\mathrm{n}(\%) .{ }^{*}$ : percentages calculated with the number of patients in each group as denominator; ": incidence is based on the number of patients experiencing at least one adverse event, not the number of events. 
TABLE 5 Summary of patients with one or more reasonably related treatment-emergent adverse and serious adverse events for all treated patients through end of study reported in $\geqslant 5 \%$ of patients in at least one treatment group

\begin{tabular}{|c|c|c|c|c|}
\hline & \multirow[t]{2}{*}{ Placebo } & \multicolumn{3}{|c|}{ Carlumab } \\
\hline & & $1 \mathrm{mg} \cdot \mathrm{kg}^{-1}$ & $5 \mathrm{mg} \cdot \mathrm{kg}^{-1}$ & 15 mg.kg ${ }^{-1}$ \\
\hline Treated patients & 28 & 33 & 32 & 32 \\
\hline Mean duration of follow-up weeks & 61 & 61 & 59 & 59 \\
\hline Mean treatment exposure doses & 11 & 11 & 11 & 10 \\
\hline Patients with $\geqslant 1$ adverse event & 28 & 32 & 32 & 32 \\
\hline Patients with $\geqslant 1$ treatment-related adverse event & $9(32.1)$ & $19(57.6)$ & $15(46.9)$ & $15(46.9)$ \\
\hline Fatigue & $3(10.7)$ & $5(15.2)$ & $1(3.1)$ & $5(15.6)$ \\
\hline Pyrexia & 0 & $2(6.1)$ & $1(3.1)$ & $2(6.3)$ \\
\hline Pain & 0 & $1(3.0)$ & 0 & $2(6.3)$ \\
\hline Pruritus & 0 & $2(6.1)$ & 0 & $2(6.3)$ \\
\hline Hyperhidrosis & 0 & $2(6.1)$ & $1(3.1)$ & 0 \\
\hline Eczema & 0 & $2(6.1)$ & 0 & 0 \\
\hline Nausea & 0 & $5(15.2)$ & $1(3.1)$ & $1(3.1)$ \\
\hline Diarrhoea & 0 & $3(9.1)$ & 0 & 0 \\
\hline Upper respiratory tract infection & 0 & 0 & 0 & $2(6.3)$ \\
\hline Headache & $1(3.6)$ & $2(6.1)$ & $1(3.1)$ & $3(9.4)$ \\
\hline Dysgeusia & $2(7.1)$ & 0 & 0 & 0 \\
\hline Arthralgia & $2(7.1)$ & $1(3.0)$ & $1(3.1)$ & 2 (6.3) \\
\hline Infusion-related reaction & $1(3.6)$ & $2(6.1)$ & 0 & $2(6.3)$ \\
\hline Hypotension & $2(7.1)$ & 0 & $2(6.3)$ & 0 \\
\hline Patients with $\geqslant 1$ treatment-related serious adverse event $\#$ & $2(7.1)$ & 0 & $2(6.3)$ & 0 \\
\hline Respiratory syncytial virus infection & 0 & 0 & $1(3.1)$ & 0 \\
\hline Urinary tract infection & $1(3.6)$ & 0 & 0 & 0 \\
\hline Peripheral neuropathy & 0 & 0 & $1(3.1)$ & 0 \\
\hline Pulmonary arterial hypertension & $1(3.6)$ & 0 & 0 & 0 \\
\hline
\end{tabular}

$5 \mathrm{mg} \cdot \mathrm{kg}^{-1}$ and $15 \mathrm{mg} \cdot \mathrm{kg}^{-1}$ groups, respectively, and the most frequently reported infection for each of the four treatment groups was upper respiratory tract infection $(18 \%, 36 \%, 16 \%$ and $34 \%$, respectively). Serious infections were infrequent across the groups $\left(18 \%, 3 \%, 19 \%\right.$ and $6 \%$ in the placebo, $1 \mathrm{mg} \cdot \mathrm{kg}^{-1}$, $5 \mathrm{mg} \cdot \mathrm{kg}^{-1}$ and $15 \mathrm{mg} \cdot \mathrm{kg}^{-1}$ groups, respectively). There were six malignancies (three nonmelanoma skin cancers with one in each of the carlumab groups, and three other malignancies with one in each carlumab group, including two lung neoplasms and one suspected, but not confirmed, neuroendocrine tumour).

$19(15 \%)$ of the 125 treated patients died (seven, one, seven and four in the placebo, $1 \mathrm{mg} \cdot \mathrm{kg}^{-1}, 5 \mathrm{mg} \cdot \mathrm{kg}^{-1}$ and $15 \mathrm{mg} \cdot \mathrm{kg}^{-1}$ groups, respectively). 14 patients died while participating in the study, while five were reported as having died after they had completed or withdrawn from the study. Six patients died due to IPF exacerbation (one, four and one in the placebo, $5 \mathrm{mg} \cdot \mathrm{kg}^{-1}$ and $15 \mathrm{mg} \cdot \mathrm{kg}^{-1}$ groups, respectively).

\section{Pharmacodynamics}

As expected, total CCL2 levels increased dramatically after initiation of carlumab (but not placebo) in a dose-proportional manner (fig. 3a), since this assay cannot distinguish between free CCL2 and CCL2 complexed with carlumab. The percentage complexed rose from $>90 \%$ to $>99 \%$ in a dose-proportional fashion. Unexpectedly, free CCL2 levels were elevated above baseline at both 24 and 52 weeks when measured at trough concentrations of carlumab (fig. 3b).

\section{Discussion}

Overall, patients who received carlumab through week 48 showed no evidence of treatment benefit compared with those who received placebo, as measured by the primary endpoint, the rate of percentage change in FVC per 4-week interval from baseline through week 52. Sensitivity and subgroup analyses on the primary endpoint showed consistent results with the primary analysis. The major secondary endpoints were also consistent with the primary endpoint. None of the three active treatment groups demonstrated benefit when compared with placebo for any of the major secondary endpoints.

Although dosing in the trial was stopped prematurely, the lack of any benefit in any endpoints and the possible worsening in some, especially in the intermediate dose group $\left(5 \mathrm{mg} \cdot \mathrm{kg}^{-1}\right)$ would seem to support 

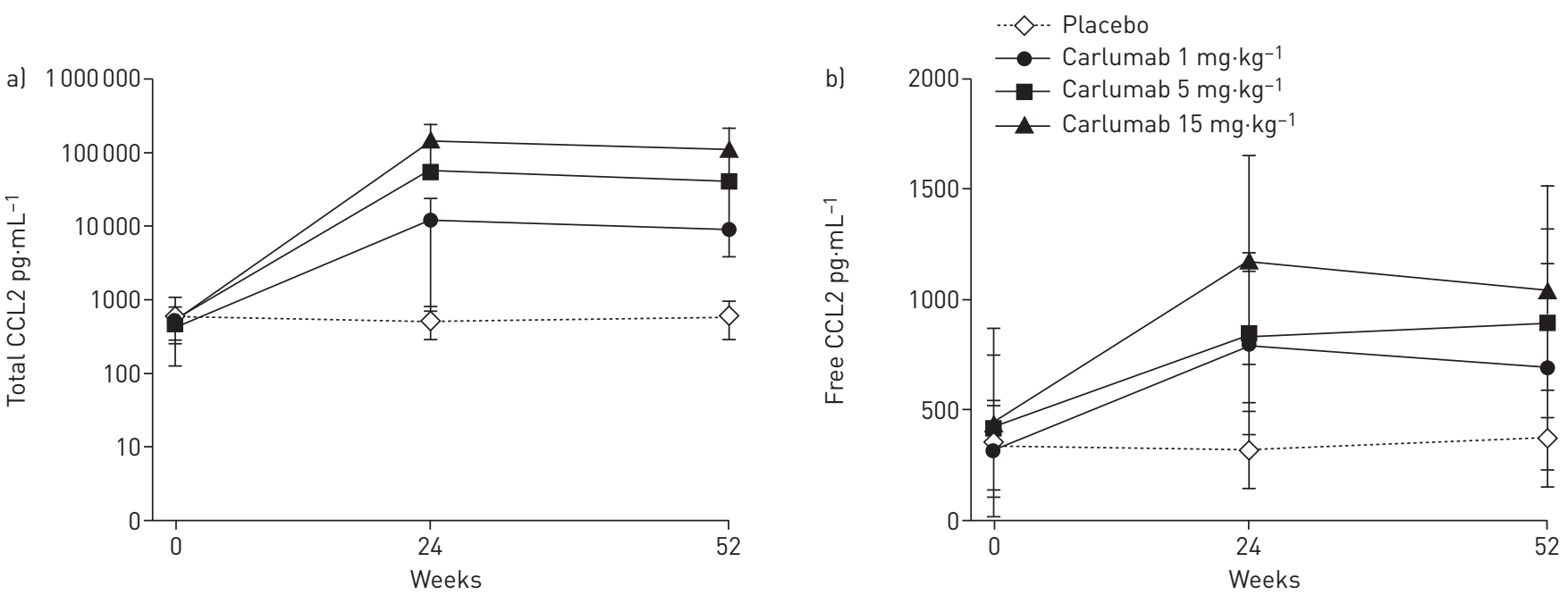

FIGURE 3 a) Total CC-chemokine ligand (CCL)2 levels over time; b) free CCL2 levels over time.

the DMC recommendations. The tendency to worse outcomes in the intermediate dose group might have been related to worse baseline characteristics in that they tended to be older, more obese, had a lower FVC, lower 6MWD and a higher use of OCS. In addition, the unexpected increase in free CCL2 levels could have possibly contributed to the trends toward worsening observed in outcomes in the higher dose groups.

In accordance with the protocol, an external DMC met to perform a pre-planned benefit-risk analysis on the week 24 data, which included an unblinded review of safety, as well as pre-specified efficacy endpoints. The DMC recommended the discontinuation of further study agent administration for patients who had been randomised to the two highest dose groups (carlumab $5 \mathrm{mg} \cdot \mathrm{kg}^{-1}$ and $15 \mathrm{mg} \cdot \mathrm{kg}^{-1}$ ) based on the observed benefit-risk profile of carlumab. After reviewing these recommendations, the sponsor opted to halt administration of study agent in all treatment groups, but to continue safety follow-up for all patients.

The results of the benefit-risk analysis suggested an absence of benefit in any treated group compared to placebo, and a trend for worsening outcomes, particularly in the $5 \mathrm{mg} \cdot \mathrm{kg}^{-1}$ group. The final results of the study confirmed these impressions. There was no benefit in any of the treatment groups regardless of the endpoint explored. As expected, the placebo group demonstrated a decline in FVC over 48 weeks $(\sim 130 \mathrm{~mL})$. While the study was adequately powered to detect significant inhibition of this decline, no effect was observed in any of the treatment groups, nor were there fewer exacerbations. Importantly, there were no differences in mortality between the groups.

A previous study with another monoclonal antibody to CCL2 failed to produce benefit in patients with rheumatoid arthritis, and there was a suggestion of worsening at the highest dose $\left(10 \mathrm{mg} \cdot \mathrm{kg}^{-1}\right)$ [32]. That study also showed a dose-dependent increase in total CCL2 levels (>2000 times baseline levels), although most of this was presumably complexed with anti-CCL2, as the report suggests that free levels of CCL2 were suppressed [32]. In another study of carlumab in cancer patients, free levels of CCL2 were able to be suppressed when measured shortly after infusion, but as early as 7 days later were at or above baseline levels [33]. These data suggest that there is a large pool of CCL2 available for binding to anti-CCL2 antibodies, but that suppression of free CCL2 for prolonged periods did not occur. This is in contrast to other monoclonal antibodies, such as omalizumab, where free target levels in serum fall and remain low until total omalizumab levels fall based on the expected pharmacokinetics of the antibody [34]. The inability to adequately suppress free CCL2 levels for extended periods of time and the observation of levels above baseline leaves open several questions. It is conceivable that there could be compensatory mechanisms by which the body increases free CCL2 levels in response to inhibition. There was a large reservoir of CCL2 able to be mobilised from the tissues based on the level of total CCL2 after therapy. The finding of free CCL2 levels above baseline, especially in patients receiving higher doses of carlumab coupled with generally worse outcomes, still leaves open the possibility that CCL2 is an important pathogenic chemokine in IPF, but that compensatory mechanisms to increase CCL2 production may have become overstimulated. Although carlumab failed to provide benefit to patients with progressive IPF, studies investigating newer agents that could more effectively suppress CCL2-mediated signalling may still be worthwhile.

In summary, this study demonstrated that treatment of IPF with carlumab did not improve lung function or reduce associated symptoms in the subset of patients who had demonstrated progression in disease. 


\section{Acknowledgements}

The authors and investigators greatly appreciate and acknowledge the patients who participated in this study. The authors also acknowledge and thank the IPF investigators and Robert Achenbach (Janssen Scientific Affairs, LLC, Spring House, PA, USA) for editorial and submission support of the manuscript.

The investigators are as follows. USA: Francis Cordova (Temple University, Philadelphia, PA), Joao De Andrade (University of Alabama, Birmingham, AL), Kevin Flaherty and Gregory Gottschlich (University of Michigan, Ann Arbor, MI), Mark Gotfried (Good Samaritan Regional Medical Center, Phoenix, AZ), Hyun Kim and Timothy Whelan (University of Minnesota, Minneapolis, MN), Yolanda Mageto (University of Vermont, Colchester, VT), Imre Noth (University of Chicago, Chicago, IL), Steven Sahn (Medical University of South Carolina, Charleston, SC) and Mary Scholand (University of Utah, Salt Lake City, UT); Canada: Martin Kolb (St Joseph's Healthcare, Hamilton, ON), Dale Lien (Walter MacKenzie HSC, Edmonton, AB), Satyendra Sharma (St Boniface General Hospital, Winnipeg, MB) and Pearce Wilcox (St Paul's Hospital, Vancouver, BC); the Netherlands: Michiel DeVries (Orbis Medisch Centrum, Sittard), Johannes Grutters (Sint Antonius Ziekenhuis, Nieuwegein), René Jonkers (University of Amsterdam, Amsterdam) and Marlies Wijsenbeek-Lourens (Erasmus MC, Rotterdam); Germany: Reiner Bonnet (Zentralklinik Bad Berka GmBH, Bad Berka); and Belgium: Michiel Thomeer (UZ Leuven, Leuven).

\section{References}

1 Raghu G, Collard HR, Egan JJ, et al. An official ATS/ERS/JRS/ALAT statement: idiopathic pulmonary fibrosis: evidence-based guidelines for diagnosis and management. Am J Respir Crit Care Med 2011; 183: 788-824.

2 Travis WD, Costabel U, Hansell DM, et al. An official American Thoracic Society/European Respiratory Society statement: update of the international multidisciplinary classification of the idiopathic interstitial pneumonias. Am J Respir Crit Care Med 2013; 188: 733-748.

3 American Thoracic Society. Idiopathic pulmonary fibrosis: diagnosis and treatment. International consensus statement. American Thoracic Society (ATS), and the European Respiratory Society (ERS). Am J Respir Crit Care Med 2000; 161: 646-664.

$4 \quad$ Meltzer EB, Noble PW. Idiopathic pulmonary fibrosis. Orphanet J Rare Dis 2008; 3: 8 .

5 Raghu G, Weycker D, Edelsberg J, et al. Incidence and prevalence of idiopathic pulmonary fibrosis. Am J Respir Crit Care Med 2006; 174: 810-816.

6 Mapel DW, Hunt WC, Utton R, et al. Idiopathic pulmonary fibrosis: survival in population based and hospital based cohorts. Thorax 1998; 53: 469-476.

7 Idiopathic Pulmonary Fibrosis Clinical Research Network, Raghu G, Anstrom KJ, et al. Prednisone, azathioprine, and $N$-acetylcysteine for pulmonary fibrosis. N Engl J Med 2012; 366: 1968-1977.

8 Noth I, Anstrom KJ, Calvert SB, et al. A placebo-controlled randomized trial of warfarin in idiopathic pulmonary fibrosis. Am J Respir Crit Care Med 2012; 186: 88-95.

9 Lee JS, Ryu JH, Elicker BM, et al. Gastroesophageal reflux therapy is associated with longer survival in patients with idiopathic pulmonary fibrosis. Am J Respir Crit Care Med 2011; 184: 1390-1394.

10 Lee JS, Collard HR, Anstrom KJ, et al. Anti-acid treatment and disease progression in idiopathic pulmonary fibrosis: an analysis of data from three randomised controlled trials. Lancet Respir Med 2013; 1: 369-376.

11 Allavena P, Bianchi G, Giardina P, et al. Migratory response of human NK cells to monocyte-chemotactic proteins. Methods 1996; 10: 145-149.

12 Carr MW, Roth SJ, Luther E, et al. Monocyte chemoattractant protein 1 acts as a T-lymphocyte chemoattractant. Proc Natl Acad Sci USA 1994; 91: 3652-3656.

13 Moore BB, Kolodsick JE, Thannickal VJ, et al. CCR2-mediated recruitment of fibrocytes to the alveolar space after fibrotic injury. Am J Pathol 2005; 166: 675-684.

14 Rose CE Jr, Sung SS, Fu SM. Significant involvement of CCL2 (MCP-1) in inflammatory disorders of the lung. Microcirculation 2003; 10: 273-288.

15 Salcedo R, Ponce ML, Young HA, et al. Human endothelial cells express CCR2 and respond to MCP-1: direct role of MCP-1 in angiogenesis and tumor progression. Blood 2000; 96: 34-40.

16 Hutchings CJ, Koglin M, Marshall FH. Therapeutic antibodies directed at G protein-coupled receptors. mAbs 2010; 2: 594-606.

17 Charo IF, Taubman MB. Chemokines in the pathogenesis of vascular disease. Circ Res 2004; 95: 858-866.

18 Flores-Villanueva PO, Ruiz-Morales JA, Song $\mathrm{CH}$, et al. A functional promoter polymorphism in monocyte chemoattractant protein-1 is associated with increased susceptibility to pulmonary tuberculosis. J Exp Med 2005; 202: 1649-1658.

19 Huang SJ, Schatz F, Masch R, et al. Regulation of chemokine production in response to pro-inflammatory cytokines in first trimester decidual cells. J Reprod Immunol 2006; 72: 60-73.

20 Ip WK, Wong CK, Lam CW. Interleukin (IL)-4 and IL-13 up-regulate monocyte chemoattractant protein-1 expression in human bronchial epithelial cells: involvement of p38 mitogen-activated protein kinase, extracellular signal-regulated kinase 1/2 and Janus kinase-2 but not c-Jun NH2-terminal kinase 1/2 signalling pathways. Clin Exp Immunol 2006; 145: 162-172.

21 Rantapää-Dahlqvist S, Boman K, Tarkowski A, et al. Up regulation of monocyte chemoattractant protein-1 expression in anti-citrulline antibody and immunoglobulin $\mathrm{M}$ rheumatoid factor positive subjects precedes onset of inflammatory response and development of overt rheumatoid arthritis. Ann Rheum Dis 2007; 66: 121-123.

22 Deshmane SL, Kremlev S, Amini S, et al. Monocyte chemoattractant protein-1 (MCP-1): an overview. J Interferon Cytokine Res 2009; 29: 313-326.

23 Bucova M, Lietava J, Mrazek F, et al. Association of chronic stable angina pectoris with MCP-1-2518 A/G single nucleotide polymorphism in the Slovak population. Clin Chim Acta 2008; 392: 71-72.

24 Jemaa R, Rojbani H, Kallel A, et al. Association between the 2518G/A polymorphism in the monocyte chemoattractant protein-1 (MCP-1) gene and myocardial infarction in Tunisian patients. Clin Chim Acta 2008; 390: $122-125$.

25 Navratilova Z, Mrazek F, Kriegova E, et al. The MCP-1-2518 (A to G) single nucleotide polymorphism in Czech patients with pulmonary sarcoidosis: association with Löfgren's syndrome. Sarcoidosis Vasc Diffuse Lung Dis 2007; 24: 33-38. 
Selman M, King TE Jr, Pardo A. Idiopathic pulmonary fibrosis: prevailing and evolving hypotheses about its pathogenesis and implications for therapy. Ann Intern Med 2001; 134: 136-151.

27 Selman M, Thannickal VJ, Pardo A, et al. Idiopathic pulmonary fibrosis: pathogenesis and therapeutic approaches. Drugs 2004; 64: 405-430.

28 Suga M, Iyonaga K, Ichiyasu H, et al. Clinical significance of MCP-1 levels in BALF and serum in patients with interstitial lung diseases. Eur Respir J 1999; 14: 376-382.

29 Moore BB, Murray L, Das A, et al. The role of CCL12 in the recruitment of fibrocytes and lung fibrosis. Am J Respir Cell Mol Biol 2006; 35: 175-181.

30 Lederer DJ, Arcasoy SM, Wilt JS, et al. Six-minute-walk distance predicts waiting list survival in idiopathic pulmonary fibrosis. Am J Respir Crit Care Med 2006; 174: 659-664.

31 Caminati A, Bianchi A, Cassandro R, et al. Walking distance on 6-MWT is a prognostic factor in idiopathic pulmonary fibrosis. Respir Med 2009; 103: 117-123.

32 Haringman JJ, Gerlag DM, Smeets TJ, et al. A randomized controlled trial with an anti-CCL2 (anti-monocyte chemotactic protein 1) monoclonal antibody in patients with rheumatoid arthritis. Arthritis Rheum 2006; 54: 2387-2392.

33 Fetterly GJ, Aras U, Meholick PD, et al. Utilizing pharmacokinetics/pharmacodynamics modeling to simultaneously examine free CCL2, total CCL2 and carlumab (CNTO 888) concentration time data. J Clin Pharmacol 2013; 53: 1020-1027.

34 Hamilton RG, Marcotte GV, Saini SS. Immunological methods for quantifying free and total serum IgE levels in allergy patients receiving omalizumab (Xolair) therapy. J Immunol Methods 2005; 303: 81-91. 